\title{
Potential risks in cross-cultural communication in construction
}

\author{
Oksana Danchevskaya* \\ Moscow State Pedagogical University, Institute of Foreign Languages, 119991, Moscow, Malaya \\ Pirogovskaya St., 1, Bld. 1, Russia
}

\begin{abstract}
Cross-cultural communication has many potential risks which occur due to errors in different spheres. In construction, interaction errors are dangerous as they can lead to serious undesirable consequences. Although there are many theoretical works on cross-cultural communication, the practical application of this knowledge is often difficult. This research is aimed to fill this gap by examining a case study with subsequent analysis of the mistakes made, evaluation of potential risks, and recommendations aimed at eliminating or at least reducing such risks. The study revealed that predominantly several errors are committed simultaneously, and by both parties on three levels: non-verbal, verbal communication, and in general behaviour. The findings indicate that possible risks can be significantly reduced or completely eliminated provided that the parties are able to competently navigate the situation. The suggested approach to studying cross-cultural communication can help people enhance the quality of interaction both in professional and interpersonal spheres.
\end{abstract}

\section{Introduction}

Humans constantly interact, and with the growth of globalization our interaction becomes more and more cross-cultural. However, when we lack knowledge about the features of a particular culture, it is easy to make mistakes which may lead to miscomprehensions or even serious conflicts. In the sphere of construction, it is especially topical as many of important construction projects today are international, and it is vital for the parties to understand each other correctly. Despite the abundance of theoretical data about different cultures and countries, it is often unclear how they function in and can be applied to everyday life. To illustrate this, many works on cross-cultural communication, after the presentation of the theory, offer so-called "critical incidents", i.e., confusing situations in communication, for discussion [1,2], yet those incidents are often either invented by the author or are not quite realistic, which does not bring all the expected benefits to the students and readers. At the same time, situations may arise when it is necessary to prepare a person or a group of people for active cross-cultural interaction in a short period of time e.g., before negotiations, a business trip, meeting a foreign delegation, moving to a

* Corresponding author: odanchevskaya@ gmail.com 
different country, going on a student exchange, etc. In such situations, people do not have the opportunity to complete a full course and thoroughly study all theoretical issues.

Here is where our approach can be useful: we propose to deduce potential risks in crosscultural communication in general and in construction in particular from already made errors, i.e., to study the errors made by others with their detailed analysis, which will provide students with easily accessible necessary tools for successful communication. The above-mentioned risks exist on all levels of interaction, but they can be significantly reduced or completely eliminated provided that the parties are able to competently navigate the situation.

The goal of this study was to examine a selection of real-life incidents with errors in cross-cultural communication. More specifically, the study aimed to achieve the following research objectives:

- To detect the cases of errors in cross-cultural communication.

- To identify the type of errors.

- To analyse and describe the causes of errors.

- To give recommendations for the avoidance of such errors, thus eliminating or at least reducing the potential risks.

This study is expected to assist a wide range of people: businessmen working with overseas partners and clients, managers and employees of international construction companies, specialists in Linguistics, Communication, and Cultural Studies, students of different areas, tourists travelling to other countries, as well as anyone who wants to improve their cross-cultural communication skills. Moreover, the suggested approach can be successfully used for educational purposes, as "learning is most effective when the learner "constructs knowledge" rather than receives it. This is an active process, enhanced by learner questions, rather than a passive process of answering teacher questions" [3].

The rest of the article is structured as follows: first, methodology is discussed, and our approach is explained. Then, the results and discussion of the study are presented in a series of nine real-life critical incidents with their analysis. Finally, general conclusions and recommendations are given, and directions for further research are offered.

\section{Methodology}

The material for the study was obtained through direct (non-participant) observation of the behaviour of people of different ethnic backgrounds, as well as from the situations of crosscultural communication during the author's interaction with the representatives of different cultures (participant observation). The incidents include situations of both professional and interpersonal communication.

The study itself is empirical and is presented in the form of case studies (a short description of real-life critical incidents) with their subsequent analysis, the evaluation of potential risks, and recommendations aimed at eliminating or reducing such risks.

As our approach is practice oriented, in this article we do not have the goal of conducting theoretical research. Nevertheless, the analysis of critical incidents and potential risks is grounded in the theoretical basis generally accepted in cross-cultural communication, mainly the classifications of cultures by E. Hall [4], G. Hofstede [5] and F. Trompenaars [6], theory of non-verbal communication [7], and politeness theory by P. Brown and S. Levinson [8]. 


\section{Results and discussion}

The incidents presented below are only a few examples of the situations that either the author witnessed or which happened to herself or her friends, used to illustrate the potential risks in cross-cultural communication. It is important to note that in the overwhelming majority of cases, several types of errors can be encountered in each incident, but for the convenience of analysis, the situations were grouped according to the most serious ones.

\subsection{Non-verbal communication}

\subsubsection{Incident 1}

Two middle-aged construction managers - a Brazilian and a Japanese - were standing in the hall of a business centre talking. The former was gesticulating a lot, while the latter hardly moved. Gradually, the Brazilian stepped a bit closer to his interlocutor, and the Japanese made an almost unnoticeable step backwards. This repeated several times: the Brazilian tried to move closer, while the Japanese tried to keep his distance. Once the Brazilian patted his companion on the shoulder, which made the Japanese start. The latter seemed to feel somewhat uneasy.

Analysis. The errors made in this case are connected with such aspects of non-verbal communication as proxemics (distance between people, physical contact) and kinesics (gestures). In general, in Latin American cultures (Brazilian) personal space considered normal between the people who are acquainted is much less than that in Asian ones (Japanese). Moreover, Brazilian people in general are more prone to physical contact and tend to touch each other during conversations, which is unacceptable in Japan. Brazilian culture is classified as emotional, while the Japanese one is neutral.

Risks. The violation of the other's personal space may be unconsciously interpreted as a threat, aggression, desire to suppress the interlocutor, which can lead to the discomfort and defensive behaviour of the latter. Excessive use of gestures may distract and irritate a more reserved person. Besides, some gestures regarded as normal in one culture, may be considered obscene in a different one. Touching someone who does not expect that may cause rejection or even anxiety.

Recommendations. It is important to observe the behaviour of the people you interact with. If they are from a different culture regarding physical contact, it is recommended for both parties to adjust to each other: to keep the personal (with acquaintances) or social (with strangers) distance appropriate (non-violation of the personal space) and to avoid unnecessary physical contact. Gestures should be used moderately and with caution, especially in formal settings.

\subsubsection{Incident 2}

The situation happened in the hall of a construction company and was observed at some distance, which did not allow to hear the conversation.

A Frenchwoman was talking to a Sudanese man. Apparently, they knew each other, but were not closely acquainted. During the conversation, the woman kept looking into the man's eyes, smiling. In the beginning, the man showed some signs of uneasiness (he was a little nervous and had an insecure posture). But later he also began to look into the woman's eyes. At some point, he touched her hand and told her something with a broad smile, to which the woman abruptly replied to him, turned around and left, looking insulted. 
Analysis. The woman's main error was in the sphere of oculesics (the length and kind of gaze). While in French culture a direct gaze is appreciated and its length is not strictly regulated, in Sudanese one such behaviour may indicate the woman's interest in the man, especially in combination with a smile. In most African cultures eye contact should be direct, but not too long or steady.

Risks. Eye contact is a very powerful means of communication, hence it should be used with caution. Too long direct gaze may be interpreted as aggression, a challenge, and can lead to a conflict. If addressed to a person of the opposite gender, it can be perceived as a sexual signal and, consequently, provoke harassment. In Muslim countries, women are expected to avoid any direct eye contact with men.

Recommendations. Eye contact is important, but it should be used correctly to do good, not harm to the interaction. Avoiding eye contact completely in most cultures would be regarded as disrespectful, while in some it is conversely. Direct gaze should be used moderately and not steadily, besides, special attention should be paid to eye contact with people of the opposite gender and higher status.

\subsubsection{Incident 3}

A Russian girl was on her first trip to Portugal to visit a friend. Every time when she was introduced to someone, each person came up to kiss her on the cheeks. She felt a bit shy but pleased, and kissed them back. She felt rather embarrassed when once her friend's colleague, a married man, also kissed her at their first meeting.

When she had dinner with her friend's family, at some point the people at table began discussing something in Portuguese, the language she did not know. They spoke louder and louder, and often interrupted each other. She felt very uncomfortable to be involved in a family quarrel and was wondering if she might be the reason for it.

Analysis. This situation has three aspects to analyse: greetings, language use, and style of communication. Greetings in the above-mentioned cultures differ: while in Portugal double kissing on the cheeks is a common way of greeting between women or people of the opposite gender, in Russia single kissing on the cheek is usually used only with close people. Language use: etiquette in all countries requires speaking a language understandable to all the participants, if such is possible. Style of communication is always culture specific: Portuguese culture is more emotional than Russian, and conversations can easily become very animated, with interruptions and highly emotional remarks. Nevertheless, it does not offend any of the participants, while in Russian culture raising one's voice to an interlocutor or interrupting him is considered impolite and aggressive.

Risks. General rules of etiquette are more or less universal, and breaking them causes discomfort to others. While different styles of greetings can hardly provoke any conflict, and can be easily adapted to, in certain official cases they can cause an awkward situation. Very loud voice, high speed of speech and interruptions in some cultures can be regarded as disrespectful and even offensive.

Recommendations. Such paralinguistic features as tone and speed of speech, volume of voice, pauses, interruptions, etc. affect both the interpretation of the verbal message and the emotional state of the participants. To avoid misunderstandings, it is important to monitor not only the content of the discourse, but also the way of its expression. 


\subsection{Verbal communication}

\subsubsection{Incident 4}

An American construction manager (married) began to work in Russia. His personal assistant was a middle-aged Russian woman (married, with a child). They had a very good professional relationship. After a couple of months, the woman wondered if he was really satisfied with her as an assistant. He did not understand the reason for her doubts, to which she replied that he had never paid a single compliment to her.

Analysis. Attitude to compliments also differs across cultures. In Russia, women expect men to pay them occasional compliments, this is a positive politeness strategy and does not imply any second meaning, while in the USA a compliment can be a negative facethreatening act and may even be interpreted by the woman as sexual harassment. One of the reasons for such attitude to compliments could be in rather different values of the index of masculinity (Russia - 36, the USA - 62 [9]).

Risks. Compliments and showing attention to people is a very subtle topic: while in some cultures they are expected, in others they are frowned upon. It is important not to go beyond the bounds of decency, on the one hand, and not to look indifferent, on the other.

Recommendations. As errors in gender relations may lead to serious misunderstandings, preliminary familiarity with the rules of a particular culture is a must. When a person is not aware of those rules, it would be safer, if a compliment is needed, to make it general, very polite and devoid of any signs of affection or anything that can be interpreted as sexual interest (e.g., you may compliment the person on his/her professional qualities).

\subsubsection{Incident 5}

An overheard conversation between a German and an Indian discussing some business matters.

German, "Are you ready to discuss all the details of the deal?"

Indian, "I'd say yes, though we'd still like to work through some points..."

German, "Well, when can we negotiate then?"

Indian, "I'm afraid it'll take some more time as my partners are not quite sure that they're ready to sign the agreement."

German, "Is there anything that worries you?"

Indian, "In general, all is fine, but we have some minor doubts..."

German, "So let's discuss everything during the negotiations. When will you be able to meet?"

Indian, "I'll do my best to have everything ready by next week."

Analysis. German communication style is direct, and Indian is indirect, which caused misunderstandings between the colleagues. While the German was persistent in achieving his goal - signing the contract within the agreed timeframe, the Indian was trying to explain to him that neither he nor his partners were ready for the deal, and that they were not satisfied with the agreement as it was. The Indian was following the guidelines of politeness typical for his culture, he could not say a direct "No", thus his refusal was very evasive to the German and was not understood. To avoid confrontation, the Indian finally agreed to the negotiations, but it was not what he really meant. Most likely in this situation, the negotiations will either not take place at all or be delayed, and will probably fail.

Risks. Failure to understand the communication style of your partner can lead to many serious issues. It is especially important in a professional context. A person with the direct style may seem aggressive, hostile, too pushy to the one with indirect style. And vice versa, 
indirect replies may seem as a manifestation of instability, insecurity, or even weakness to someone who is used to direct style.

Recommendations. It is useful to be aware of the communication style typical of the culture of your interlocutor to avoid vain expectations, as well as to adapt your own style to make the communication more successful.

\subsubsection{Incident 6}

An Irishman went to work in Russia as a top manager in a big construction company and had to meet his boss almost every day. The head of the company was a middle-aged Russian man. At their first meeting, they were properly introduced to each other using their full names and job titles. Further on, during their communication, the Irishman addressed his boss by his first name, and once in the cafeteria the former asked if the latter would not mind if he joined him for lunch, and sat at table. After some time, the Irishman noticed that his colleagues were looking at him suspiciously, and his boss was trying to avoid talking to him except in business situations.

Analysis. Power distance index in Russia is high (93 [9]), and hierarchy is important. This includes addressing your superiors by their first and middle names, avoiding familiarity, and being respectful. In Ireland, power distance index is much lower (28 [9]), that explains the Irishman's behaviour with his boss.

Risks. Non-observance of the norms of communication accepted in a particular culture can lead to professional and personal conflicts.

Recommendations. Power distance index greatly determines situations of formal communication, therefore it is recommended to pay attention to such differences. In any culture, the best way is to address a person officially (according to the requirements of a particular culture) unless the person him- or herself asks to be addressed differently. Personal boundaries are to be respected in any situation.

\subsection{General behavioural errors}

\subsubsection{Incident 7}

An Englishman invited his Argentinian friend to dinner at his place. During the conversation with the Englishman and his wife, the Argentinian was asking many questions as he wanted to know more about English culture. He was also interested in real estate business, so he asked how much a house like theirs could cost and if they could afford it with their salaries. The Englishman explained that prices tend to change, and that they had bought the house years ago, so he did not know the actual price then. Still, the Argentinian wondered how much his friend earned as a banker and if it was difficult for them to pay for their son's education in an American university. There was a pause, and then the wife replied that they earned enough for them to have a normal life, after which she immediately changed the topic.

Analysis. The Argentinian's main error was to address taboo topics in English culture, in this case - money matters (people's income, their expenses). As the English are the representatives of a low-context culture and are much more individualistic (89 percent against 46 [9]) and reserved than high-context Argentinians, they feel uncomfortable discussing such personal topics even with friends.

Risks. Though there are some universal taboo topics, some of them can be culturally specific, and bringing them up in a conversation might turn people away from you as this can be perceived as a violation of their privacy and being very impolite. 
Recommendations. The most reasonable behaviour in any culture would be to avoid asking too personal questions and discussing controversial topics which might be taboo ones. Normally, unless you are close friends, these include, but are not limited to: people's income, health problems, family issues, sexual life, death, religious and political views.

\subsubsection{Incident 8}

A Cuban came to Russia and wanted to see his Russian friend, a girl he knew. They arranged a meeting, and the girl was waiting for him at the right time and place. When fifteen minutes passed and he was not there, she called him, and he said that he was almost there. Another fifteen minutes later she called him again; that time he told her that he had got into a traffic jam in a taxi and would be a little late. When he arrived, around fifty minutes later than the previously arranged time, smiling and making a joke about his being late, she did not seem so happy to see him.

Analysis. Though both cultures are polychronic, in Russian one, punctuality is very appreciated, and it is considered especially rude for a man to be late for a meeting with a woman. If someone is being late, he is expected to inform the other person as soon as possible and to apologise (which was not the case in the described incident). In contrast, Cuban (like most Latin American) culture allows delays, and being late is considered absolutely normal, sometimes even for an official meeting.

Risks. Attitude to time also differs, and it is important to follow the generally accepted rules. When a person (A) from a culture where punctuality is very important deals with someone (B) in whose culture it is not such a value, they may have conflicts: A will be annoyed by B being constantly late, missing important meetings, wasting A's time and breaking deadlines, while $\mathrm{B}$ will be annoyed by A being so strict and pushy about punctuality and may have problems understanding what he does wrong.

Recommendations. As perception of time varies across cultures, it is necessary to learn that of your partners beforehand to know what to expect. Regardless of the situation, it is recommended to value other people's time and be punctual, as well as observe any set deadlines - such kind of behaviour will be appreciated in any culture.

\subsubsection{Incident 9}

A Russian was invited to visit the family of her Chinese friends for the first time. The girl decided to bring some flowers and a small gift, so she bought a bouquet of beautiful white chrysanthemums and a set of four nice tea cups. She knew wrapping was important in Chinese culture, so she had the box of cups wrapped in blue paper. When she arrived, many surprises were awaiting her. First, the hostess looked confused while receiving the flowers, but thanked the girl. Then, the host refused to accept the gift, and he accepted it only after the girl insisted; still, she noticed that he felt uncomfortable taking it. And finally, when some time later they unwrapped the box, they glanced at each other gravely. However, though the atmosphere felt tense, nobody made any comment to her.

Analysis. The Russian girl was acting according to the norms of her culture. Both in Russian and Chinese cultures it is considered good manners to bring something to the hosts when you are invited to someone's house. Nevertheless, the girl made several errors, which show that she lacked the knowledge about the specific features of Chinese culture: white flowers in general and chrysanthemums in particular are associated with funerals and mourning, as well as the blue colour of the wrapping. Nothing should be given in four pieces as in Chinese the words "four" and "death" sound similar. Moreover, Chinese people may refuse two or three times before accepting the gift, this is done out of politeness. 
Risks. Every culture has its norms, beliefs and superstitions. Gift-giving and visiting people are among the most delicate aspects as the slightest mistake can lead to unfortunate misunderstanding or even offence, and can negatively affect the relationship.

Recommendations. Special attention should be paid to such details as colour and number symbolism in different cultures, the meaning of particular gifts, the necessity of a wrapping, the attitude to odd and even number of flowers, the anticipated behaviour while visiting people, etc.

\section{Conclusions}

This study investigated the potential risks that may arise in the process of cross-cultural communication in general and in the sphere of construction in particular and can lead to a number of problems, such as: serious misunderstandings, loss of and/or threat to face, violation of social norms, offence, hostility, various types of conflicts, and as a result failure of negotiations, supply disruptions, violation of deadlines, etc. For this purpose, we examined real-life critical incidents analysing the errors made, the risks caused by them, and giving the recommendations to avoid them. Thus, these results are an important addition to the theoretical study of the issue.

As can be seen from the above examples, in many cases several errors are committed simultaneously, and by both parties. Such errors predominantly occur on the following levels: non-verbal communication (proxemics - violation of physical personal boundaries; kinesics - inappropriate gesticulation, postures, mimics and physical contact; eye contact mistakes), verbal communication (face-threatening acts, using unsuitable forms of address, direct vs. indirect expression, being politically incorrect, etc.), and general behaviour (misconduct at introductions, visiting people, greetings and taking leave, gift-giving, hospitality, discussion of taboo topics, delays and breaking deadlines, and many more). Obviously, it is impossible to know in detail the characteristics of all cultures, and even experienced specialists can sometimes make mistakes. The main goal is to avoid really serious ones, and for this purpose, if possible, it is advisable to get acquainted with the culture before entering into dialogue with its representatives. Deep theoretical knowledge will always help to navigate in an unforeseen situation, and in combination with learning from other people's errors, it will prepare anyone for successful interaction.

This study is aimed to bridge the gap between theory of cross-cultural communication and its practical application, as well as to help people enhance the quality of such interaction both in professional and interpersonal spheres.

\section{References}

1. S. Apedaile, L. Schill, Critical incidents for intercultural communication, Edmonton, AB: NorQuest College (2008)

2. A. Holiday, M. Hyde, J. Kullman, Intercultural communication, London, N.Y.: Routledge (2010)

3. V. Borkovskaya, W. Bardenwerper, R. Roe, Interactive teaching of risk management in the Russian construction industry, IOP Conf. Ser.: Mater. Sci. Eng. 365, 062030 (2018)

4. E.T. Hall, Beyond culture, N.Y.: Anchor Books (1989)

5. G.H. Hofstede, Culture's consequences: Comparing values, behaviors, institutions, and organizations across nations, 2nd ed., Thousand Oaks, CA: SAGE (2001)

6. F. Trompenaars, C. Hampden-Turner, Riding the waves of culture, London: Nicholas Brealey Publishing (1997) 
7. M.L. Knapp, J.A. Hall, T.G. Horgan, Nonverbal communication in human interaction, 8th ed., Boston: Cengage (2013)

8. P. Brown, S. Levinson, Politeness: Some universals in language usage, Cambridge: Cambridge University Press (1987)

9. Hofstede insights, Country comparison, On-line: https://www.hofstedeinsights.com/country-comparison/ 